\title{
On the Reading Promotion Mode of Aviation Colleges Library
}

\section{Chunhong Zhang}

\author{
Shenyang Aerospace University \\ sy_zch@sina.com
}

Keywords: Aviation colleges; University library; Reading promotion; Reading mode

\begin{abstract}
In Combination with actual case of Shenyang aerospace university, This paper discusses the aviation colleges students' reading situation and the necessity of developing promotion of reading and elaborates the school reading promotion binding mode based on credit and open reading promotion model . University Library bears the responsibility to promote reading, so it should actively promote with high sense of responsibility to improve college students the consciousness of learning and reading.
\end{abstract}

\section{Introduction}

University library is the hall of the spread of knowledge, the holy land of the majority of teachers and students to read. It's collection of books has the characteristics of professional, authoritative and comprehensive, Extensive and unique collection of resources make it a main position to promote reading culture. With the advent of the information age and the development of digital technology, the reading methods and patterns of college students have changed. Aviation College Students of science and engineering is given priority to, more boys school students read fewer books. In order to solve the present situation, the library should host the series of activities or related courses to improve students' interest in reading.

With the continuous expansion of college enrollment, social competition is more intense, for college students, employment pressure is more severe, how to integrate into the community as soon as possible, it is the problem that must be faced for the contemporary college students .In other words, every college students have put forward higher requirements because of the arrival of the information age. Students must have a strong comprehensive quality, including learning ability, innovation ability, cooperation ability, information quality and so on. And the improvement of learning ability depends on the extracurricular reading in University awfully, through various forms of reading activities to improve students' autonomous learning ability.

\section{The Current Situation of Students' Reading in Aviation College and Universities}

At present, the reading situation of students in aviation colleges presents a little reading time, reading with "fast food" mainly, reading ability is not strong, reading content is single and so on ${ }^{[1]}$. There are many students in extracurricular reading time every day less than 1 hours, there are quite a number of students have not been to the library, do not know what the library resources; students' reading is mainly in the form of fast food, the lack of classic reading and deep reading, resulting in the weakening of the function of language, reduce the understanding of the text reading ability; most of the content and curriculum learning, exam, skill training, lack of humanistic reading, influence students' personal development, will be a lasting impact on the moral level of the whole society; mobile phone reading dependence is serious, and the students use mobile phone to read most of leisure and entertainment, and academic reading little; mobile phone reading occupies a lot of spare time, thinking of the college students' reading more scarce, more difficult to form a healthy personality; the students' reading ability is not strong, aviation colleges of technology, navigation Empty theory learning, ignoring human education, resulting in Aviation College Students of language feeling ability is declining, reading ability gradually degraded. In view of the above Aviation College Reading Situation and adverse effects, the library should actively action, adopt a variety of model to carry on reading promotion activities, guide students in science, health reading, 
to improve students' comprehensive quality.

\section{The Necessity of Carrying out Reading Promotion Activities in Aviation Colleges and Universities}

Aviation colleges and universities refer to the higher education institutions with the specialty of aviation, including the main body of the school. Such as, the national key universities, colleges and universities, vocational colleges. With the continuous reform and development of the national economy, the aviation industry in the national economy has become an important position in the increasingly prominent. Current aviation industry is the country's important strategic industries, aviation industry development of economic construction and national security are more and more significant. Therefore, countries of the aviation industry, support and policy tendency is becoming more and more obvious. In the era of the national development of the aviation industry, aviation colleges and universities encountered a good opportunity for development. As an aviation college, training of aviation professionals has an absolutely important role in the development of the aviation industry, so aviation colleges and universities are more responsible than ever before. Students of aviation colleges and universities must be able to meet the needs of the aviation industry, how to train qualified personnel is a historic task in the face of aviation colleges and universities. As educators, we must take the responsibility of the state and society to do the education, so that education can meet the expectations of the society[2].

In such a large environment, the training of qualified personnel is an important responsibility of the Aviation College. It is a very difficult problem to improve the students' reading quantity and reading comprehension in the present information technology, which affects people's life in a wide range. The way in which people are familiar with the paper reading has been declining year by year. The new generation of college students are more accustomed to electronic products and the use of media access to information, more than the impact of paper reading. According to CTR market research, media and product research institute CNRS (National readership survey) in May 2008 - October compared with the same period in 2007 data. Five media (TV, the Internet, newspapers, magazines, radio), network users the largest increase, audience crowd of $80 \%$ for young people under the age of 30, the student users not in the minority. At the same time, all kinds of audio and video products have come to the fore, in college students formation new hot impact of paper reading [3]. Therefore, the library has responsibility and obligation to carry out actually feasible reading promotion activities, let the majority of students to love reading, deep reading.

\section{Restricted Reading Promotion Model Based On Credit System}

Target. < the CPC Central Committee and the State Council on strengthening and improving the ideological and political education of college students views $>$ pointed out, at the same time of strengthening the ideal and belief education of college students, patriotism education and moral education, but also "Taking the comprehensive development of college students as the goal, carrying out quality education, in particular, strengthening " humanity quality and scientific spirit education ". Based on the guiding ideology of training the knowledge, ability, quality coordinated development and comprehensive improvement and highlight the innovation ability training for outside of class to create a good atmosphere for education, promoting the development of personality, Shenyang aero space University developed undergraduates extracurricular training plan. In the extracurricular training program requirements, students each semester to submit at least a book report, each report can be obtained at most 0.2 credits, they must fill 1-2 credits before graduation. The core of this course is making students to obtain ideological education and spiritual sublimation at the same time they get credit when they were provided with the appropriate bibliography [4].

Process Control. At the beginning of the course, teachers recommend the reading list to students, according to the characteristics of the stage of the growth of students, and recommend the relevant bibliography for different stages. 
Table 1 freshman to senior student subject name

\begin{tabular}{|l|l|l|}
\hline GRADE & Bibliography Subject Name & Purpose of Cultivation \\
\hline Freshman & $\begin{array}{l}\text { Moral education project, mental health education } \\
\text { project, Biography of the characters, etc. }\end{array}$ & $\begin{array}{l}\text { Establish a correct outlook } \\
\text { on life }\end{array}$ \\
\hline Junior Student & $\begin{array}{l}\text { Aesthetics project, history project, geography project, } \\
\text { etc. }\end{array}$ & $\begin{array}{l}\text { Cultivation of literature and } \\
\text { art } \\
\text { social science project, military project, etc. }\end{array}$ \\
\hline Senior Student & $\begin{array}{l}\text { Career planning and social life project, world politics } \\
\text { project, foreign literature project, etc. }\end{array}$ & $\begin{array}{l}\text { Prove the comprehensive } \\
\text { quality }\end{array}$ \\
\hline $\begin{array}{l}\text { Master the way of doing } \\
\text { community, } \\
\text { comprefore Going into the }\end{array}$ \\
\hline
\end{tabular}

a. Scale of Marks

1) The argument right: the claim must be reasonable, to avoid subjective, arbitrary and one-sided, accord with theory and practice, withstand scrutiny and test.

2) Clear-cut argument: proposition attitude should be clear that the entire concept and the judgment to have clear meanings, vague and ambiguous point of view.

3) Argument conclusive: the material presented, the data should be very fully accurate, accurate, source provenance to be clearly identified.

4) Rigorous reasoning: the process of using an argument to prove an argument is to conform to the law of logic. The argument and argument, argument and argument, the chart and the text, the beginning and the end, all logical consistency.

5) Explicit expression. Specification: expression must be clear, text and language is distinct, concise and fluent, rhetoric decency, structure is clear, focused, tail echo. The formula to strictly correct, the chart clearly endowed with beauty, the use of the use of quantities and units, graphics and Tolerance Symbols and the simplified characters used to in line with international, national standards and the competent departments of the provisions.

Result Query Selected bibliography query results to achieve network, students can access their results in any place. Through a year of independent research and development, Shenyang aerospace university Library completed the extracurricular selected bibliography achievement system. The system realize selected bibliography of the network performance management, students can find any semester scores and total score, for students to manage their own achievements. Students can inquiry and personal class query, individual query student number, name, etc. and they can also be class performance of the export volume.

In short, the purpose of the university library promoting effective extracurricular reading is to improve students' reading literacy, cultivate their access to lifelong reading ability, to help them learn to study independently. The Central Committee Vice President Professor Zhu Yongxin once said: "a person's mental development history is the history of reading. The spirit of a nation depends on reading level". A school without reading will never be a real education. University library plays an important role in the promotion of reading, especially the traditional reading is forgotten by readers period, library should increase efforts to take various measures to attract students to the library to draw nutrients in the library, in order to make in Colleges and universities can be more free, broad diving, flying.

\section{References}

[1] Wang Yingzhe. Reading promotion mode of Higher Vocational College Library [J]. Chinese and foreign entrepreneurs .2014 , 31(9): 254-255,259;

[2] Zhang Tao. On the implementation path of College Students' Humanistic Spirit Cultivation in 
aviation colleges [J]. Journal of Suzhou College of Education. 2014,15(2):74-76,79;

[3] Zhao Danni. Analysis on the [J]. Reform and opening of the reading culture construction of University Library . 2010 , 29(5):175,198 ;

[4] Yan Ge Wu, Li Chun, Li Qin. University Library Reading Promotion Mode Analysis and research: Taking the library of Hainan University as cases [J]. Agricultural Library Journal 2014, 26(5):134-137.

[5] Wu maorong, Yang liu. A study on the harmonious development of University Library Culture and campus culture -- Taking Hunan Agricultural University as an example [J]. Journal of Library and Information Sciences in Agriculture.2015,25(5):118-120

[6] Peng chunlin, Zhangruiyun. On the construction of library culture based on the digital environment [J]. Journal of the LAN TAI world.2015,(1):138-139

[7] Li qiuqi. On College Library Culture Construction [J]. Science Journal.2015,(8):184-185.

[8] Li chunhua. Thinking about the influence of the Internet age on the culture of University Library [J]. Culture Journal.2015,(3):180-182

[9] He jing,Chen ying, Li ting. Analysis of the Regional Character of the Library Culture [J]. Journal of Library Construction.2014,(10) : 6-8

[10] Wei jianghui. Probe into the cultural service of University Library in the information age [J]. Journal of Higher Education.2015,(4):220-222 